\title{
ATRIAL DISSOCIATION AND DOUBLE ATRIAL ARRHYTHMIAS
}

BY

\section{M. SANGHVI}

From the Department of Cardiology, Sawai Man Singh Hospital and Medical College, Jaipur, India

Two independent sets of $\mathrm{P}$ waves have occasionally been observed in the electrocardiograms of experimental animals and attributed to dissociated activity of the two atria (Condorelli, 1929; Scherf and Siedek, 1934). The studies of Marcel and Exchaquet (1938) on the human fœtus strongly suggest that atrial dissociation occurs in man, and electrocardiograms have also been illustrated and reported to show this phenomenon. The evidence in clinical cases was, however, not considered as conclusive by Lewis (1925), Katz (1946), White (1951), and Scherf and Schott (1953) because the possibility of artefacts could not be ruled out. Deitz et al. (1957) who reviewed the reported cases recently, considered some of the illustrations (Bay and Adams, 1932; Lombardini and Aviles, 1939; Moreira, 1951; Bellet, 1953) to be good or convincing examples of atrial dissociation, and reported three cases observed by them. Even in one of their three cases, however, artefact has been considered a reasonable possibility by Diamond and Hayes (1958). In almost all the cases reported to show atrial dissociation, the voltage of the secondary set of $P$ waves has been very small and sometimes appreciable only on magnification. The purpose of this paper is to present electrocardiograms of a patient showing a clear secondary set of $P$ waves with a voltage as high as $12 \mathrm{~mm}$., undoubtedly demonstrating the phenomenon of atrial dissociation.

\section{Case Report}

A housewife, aged 46, complained of transient attacks of præcordial discomfort and palpitation, lasting from a few seconds to a few minutes, for the past three years. She stated that the attacks appeared only when her pulse rate exceeded 100 a minute. A thyroid adenoma had been present for the past 7 years, but there was no clinical or laboratory evidence of hyperthyroidism. A 12-lead cardiogram showed sinus tachycardia with a rate of 120 a minute. In lead V6 one unusual premature complex was recorded. Just after this lead had been recorded the patient complained that she was getting one of her usual attacks, and further records of lead V6 now showed an unusual arrhythmia. The records (Fig. 1) were taken intermittently at intervals of 2-3 seconds throughout the paroxysm which lasted about a minute. The tracing taken the next day was normal with a rate of 75 a minute. Further attempts to obtain a record during a paroxysm failed as these were transient and subsided before the patient could reach the hospital. The paroxysms have been controlled by administration of quinidine sulphate by mouth in a dose of 3 grains twice daily.

Electrocardiograms. Fig. 1A shows leads V5 and V6 recorded just before tracing B was obtained. Lead V6 shows one premature ectopic $P$ wave (marked X) during undisturbed sinus rhythm. Other records are of V6. In B, biphasic $P$ waves with a voltage of about $10 \mathrm{~mm}$. occur at intervals of 0.14 to $0.18 \mathrm{sec}$. at a rate of 330 to 430 a minute. These $P$ waves are ectopic in origin because the sinus $P$ waves in other records are different in contour. In $C$, upright sinus $P$ waves are seen preceding the 5 th and the 7 th $\mathrm{QRS}$ complexes. The ectopic $P$ waves are biphasic with a voltage of $12 \mathrm{~mm}$., and of a slightly different contour from those in record B, with a broad Ta. The ectopic P-P interval gradually increases from 0.26 to 0.34 sec., with a corresponding decrease in rate from 230 to 176 a minute. In $D$, the ectopic $P$ waves with a voltage of $6 \mathrm{~mm}$. and a broader Ta segment occur at intervals gradually increasing from 0.40 to $0.92 \mathrm{sec}$., with decrease of the rate from 150 to 65 a minute. Sinus $P$ waves are seen preceding most of the QRS complexes with a P-R interval of 0.12 sec. except when they are deformed by superimposed ectopic $P$ waves. At some places there are very fine oscillations of the baseline with a rate of about 1500 a minute and which are independent of the other two sets of $P$ waves. In $E$, recorded just after $D$, there is a return to normal sinus rhythm. In Fig. 2, the two strips are magnified views of portions of the upper and lower strips of record D, Fig 1, showing microflutter or microfibrillation waves. 


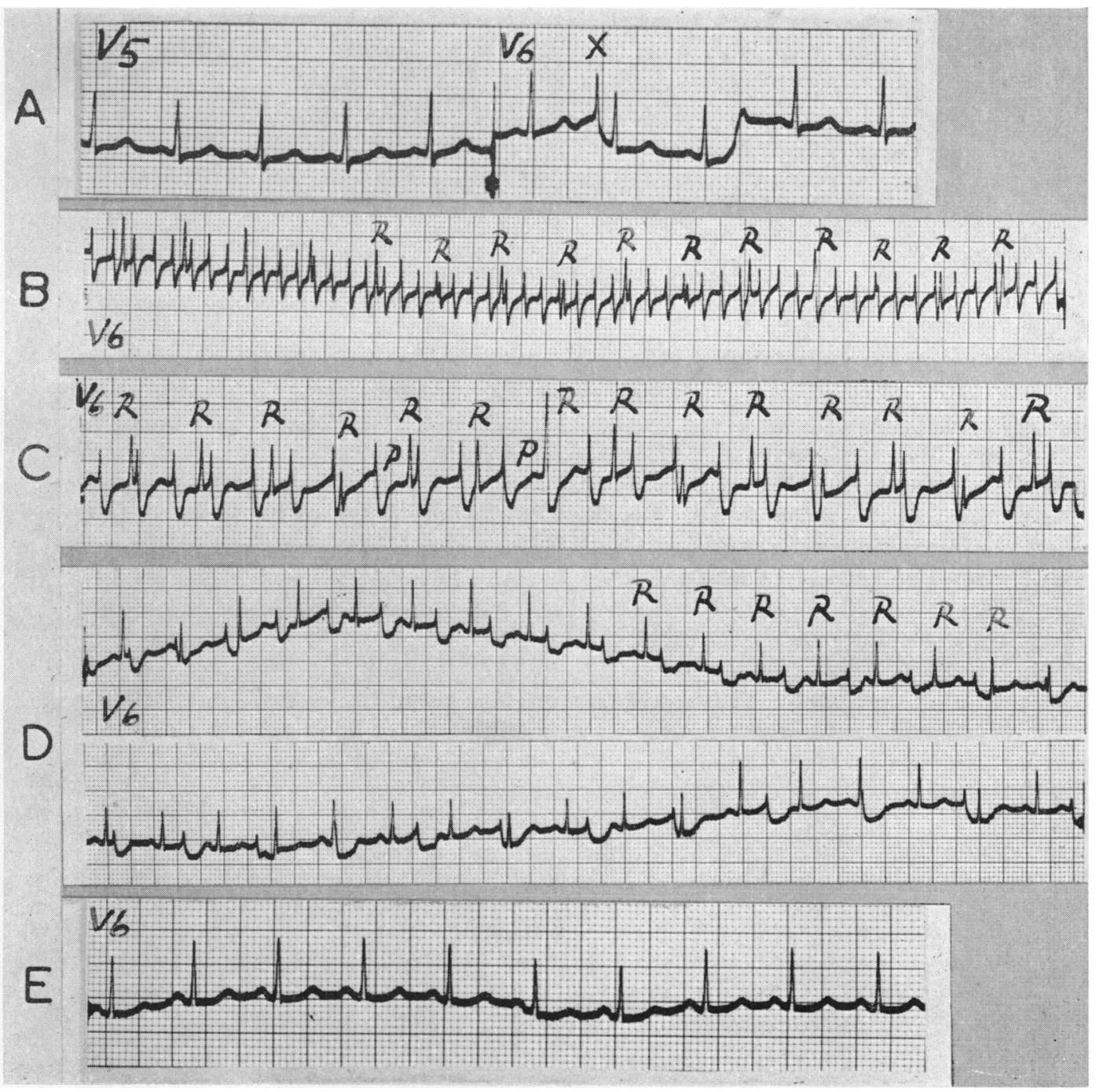

Fig. 1.-A, B, C, D, E, are successive records taken during the paroxysm. A shows leads V5 and V6. The other records are all of V6. The two strips of D are continuous. For description, see text.

\section{Discussion}

In the case reported here, the QRS complexes appeared regularly at a constant rate of 120 a minute before, during, and after the period of arrhythmia (Fig. 1, A-E). Sinus P waves are not discernible in record $\mathrm{B}$ apparently because of superimposed rapid ectopic $\mathrm{P}$ waves, but they are discernible in two beats in record $\mathrm{C}$ and in most of the beats in record $\mathrm{D}$ in which the etopic $\mathrm{P}$ rate has slowed considerably. It becomes clear in record $\mathrm{D}$ that normal sinus rhythm continued without interruption and at a constant rate throughout the paroxysm of arrhythmia, and that the sinus impulse was conducted to the ventricles.

An independent set of ectopic $\mathbf{P}$ waves is visible in records $\mathbf{B}, \mathbf{C}$, and $\mathbf{D}$. The ectopic rhythm does not disturb the regular sinus rhythm and the ectopic $P$ waves are therefore not conducted to the ventricles. These clear ectopic $P$ waves undoubtedly prove the existence of an independent 


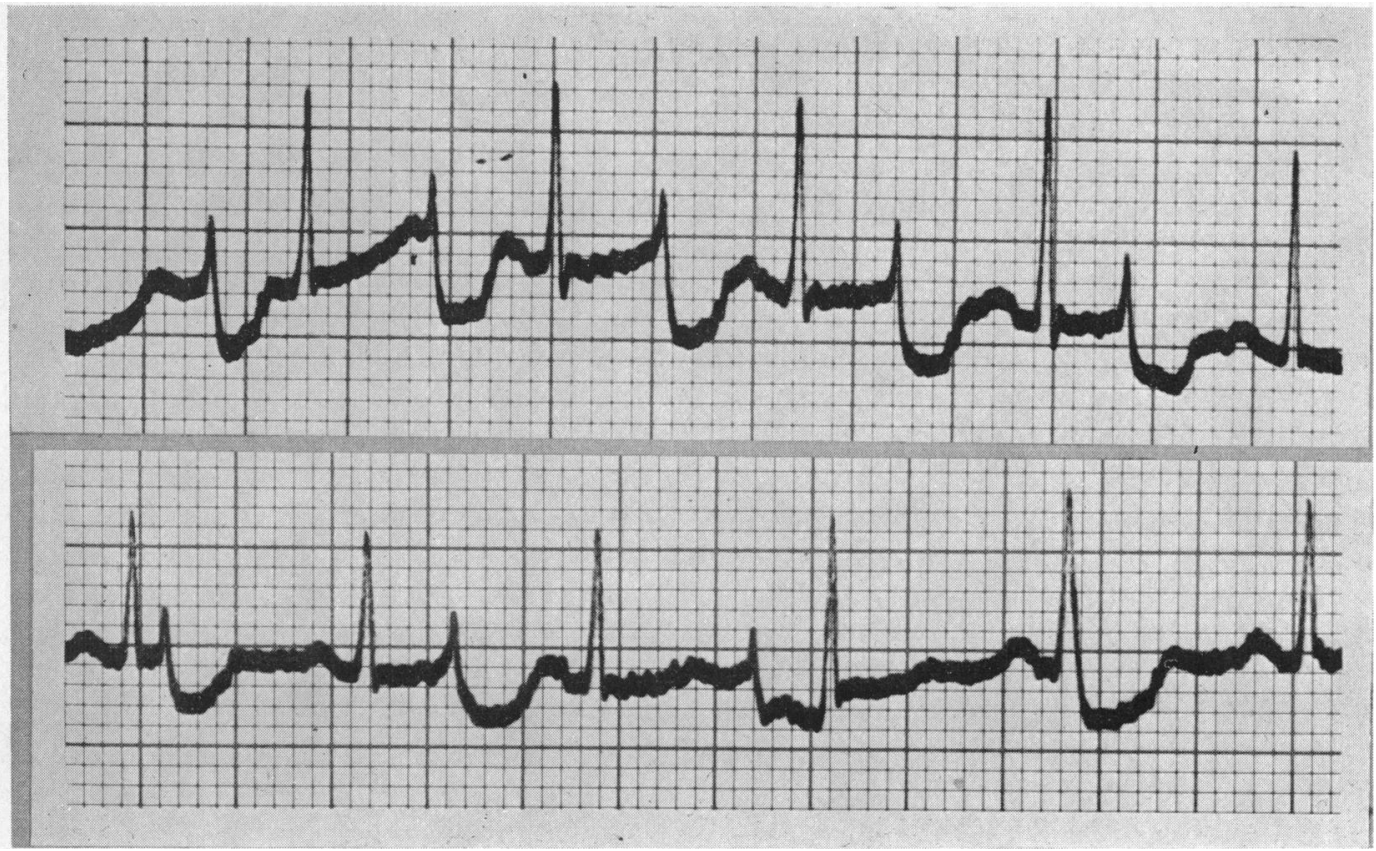

FIG. 2.-Upper record, magnified view of part of upper strip of Fig. 1(D). Lower record, magnified view of part of lower strip of Fig. 1 (D).

ectopic atrial rhythm completely dissociated from the normal sinus rhythm. Ectopic secondary $P$ waves of a voltage as high as 6 to $12 \mathrm{~mm}$. have not been recorded in any of the previously reported cases of atrial dissociation. The slightly irregular ectopic rhythm in record B with a rate of 330 to 430 a minute may be interpreted as atrial flutter, and that in record $C$ with a rate of 230 to 176 as atrial tachycardia. In record $D$ the ectopic rate decreases until it is only 65 a minute, nearly half the sinus rate. The records thus show a gradual transition from flutter or tachycardia to bradycardia until finally the ectopic focus of impulse formation becomes extinct. The records thus clearly demonstrate the concept of unitary nature of the auricular arrhythmias (Prinzmetal et al., 1952). In the present case, however, the arrhythmias are localized to one atrium or to a part of one atrium, while the sinus $P$ waves continue without interruption and are regularly conducted to the ventricles.

In parts of record $D$ there may be seen, in addition to the two sets of $P$ waves, very fine and rapid oscillations of the baseline having a rate of about 1500 a minute. A magnified view of portions of this record (Fig. 2) shows typical saw-tooth like oscillations in several places. Paroxysms of such fine waves have been previously illustrated and were believed to represent an independent focus and atrial dissociation (Deitz et al., 1957). If this is interpreted as showing rapid microflutter or fibrillation, a third independent focus of impulse formation must be present in the atria. The possibility of artefacts cannot, however, be ruled out.

Two types of double atrial arrhythmias appear to be more or less satisfactorily illustrated in previous reports. (A) Normal sinus or supranodal rhythm in the right atrium associated with, in the left atrium (i) flutter (Lombardini and Aviles, 1939; Bellet, 1953; Mussafia and Jacovella, 1957); (ii) fibrillation (Condorelli, 1929; Moreira, 1951; Deitz et al., 1957; Sanchez and Varela, 1958; Marques, 1959); (iii) a combination of tachycardia, flutter, and fibrillation (Deitz et al., 1957). (B) Parallel sets of atrial waves (Bay and Adams, 1932; Deitz et al., 1957; Marques, 1958; Diamond and Hayes, 1958). The case reported here is unique in that it illustrates clearly each one of these arrhythmias and, perhaps, also a second pararrhythmic centre of impulse formation. Both centres 
are presumably located in the left atrium, and are apparently protected against each other as well as against the sinus impulse by protective entrance and exit blocks.

The occurrence of two sets of independent $P$ waves has been attributed to two active $S-A$ nodes (Schrumpf, 1920), anatomic and functional separation of the S-A node in two parts (Bay and Adams, 1932), interatrial block due to occlusion of the blood supply with each atrium in toto becoming separately autonomous (Condorelli, 1929; Scherf and Siedek, 1934), and varying sinu-atrial block with prolongation of conduction time to one of the atria (Decherd et al., 1946). The phenomenon has recently been attributed to dissociation of a part of atrial myocardium with ectopic impulse formation and protective entrance and exit block or dynamic bidirectional block (Deitz et al., 1957; Marques, 1958 and 1959; Sanchez and Varela, 1958). This concept is supported by the observation of dissociation of a small part of atrial muscle in the dog's heart after intoxication with strophanthin (Lewis et al., 1921) and yohimbine (Tait, 1910). It is also supported by the clinical studies of Giraud et al. (1955) on intracardiac potentials. These workers found in cases of atrial fibrillation, several independent areas with rhythmic and co-ordinated activity separated by wandering boundaries from the remainder of the atria, with disorganized activity, typical of fibrillation, indicating that two, or more, pararrhythmic centres mutually protected against each other's impulses might be present in the atria. In the present case the paroxysm was transient, and the ectopic impulse formation can be attributed to a temporary functional disturbance associated with increased irritability of the atrial myocardium (presumably the left atrium) giving rise to pararrhythmic foci of impulse formation which were apparently protected both against each other and against the sinus impulse by protective entrance and exit blocks. There was also an associated hyper-irritability of the sinus node resulting in sinus tachycardia.

\section{Summary}

Electrocardiograms of a patient are presented which show a transient paroxysm of double atrial arrhythmias probably due to pararrhythmic centres of impulse formation in the left atrium.

Dr. L. R. Sarin, Superintendent, S.M.S. Hospital, kindly permitted the publication of this report.

\section{References}

Bay, E. B., and Adams, W. (1932). Amer. Heart J., 7, 759.

Bellet, S. (1953). Clinical Disorders of the Heart Beat. p. 132-34. Lea \& Febiger, Philadelphia.

Condorelli, L. (1929). Ztshr. ges. exper. Med., 68, 516. Cited by Decherd et al.

Decherd, G. M., Ruskin, A., and Brindley, P. (1946). Amer. Heart J., 31, 352.

Deitz, G. W., Marriott, H. J. L., Fletcher, E., and Bellet, S. (1957). Circulation, 15, 883.

Diamond, E. G., and Hayes, W. L. (1958). Amer. Heart J., 56, 929.

Giraud, G., Latour, H., and Puech, P. (1955). Amer. Lab. Cardiol. Clin. Med., 47. Cited by Marques (1958).

Katz, L. N. (1946). Electrocardiography. 2nd ed. p. 772. Lea \& Febiger, Philadelphia.

Lewis, T. (1925). The Mechanism and Graphic Registration of the Heart Beat. 3rd ed., p. 186. Shaw and Sons, London.

- Drury, A. N., and Ilescu, C. C. (1921). Heart, 9, 21. Cited by Deitz et al.

Lombardini, R. V., and Aviles, M. D. (1939). Rev. argent. cardiol., 5, 380. Cited by Deitz et al.

Marcel, M. P., and Exchaquet, J. P. (1938). Arch. Mal. Coeur, 31, 504. Cited by Marques (1958).

Marques, M. G. (1958). Brit. Heart J., 20, 335.

- (1958). Cardiologia, 34, 227. Abstracted in Exc. Med. Cardiovas. Dis. (1960), abstr., 142.

Moreira, J. A. (1951). Clin. Contemp., 5, 328. Cited by Deitz et al.

Mussafia, A., and Jacovella, G. (1957). Cardiologia, 31, 173. Cited by Marques, 1958.

Prinzmetal, M., Corday, E., Brill, I. C., Oblath, R. W., and Kruger, H. E. (1952). The Auricular Arrhythmias. Charles C. Thomas, Springfield, Ill.

Sanchez Cascos, A., and Varela De Seijas, J. (1958). Rev. clin. esp., 78, 143. Abstracted in Exc. Med. Cardiovas. Dis. (1959), abstr. 3205.

Scherf, D., and Schott, A. (1953). Extrasystoles and Allied Arrhythmias. p. 188. William Heinemann, New York and London.

-, and Siedek, H. (1934). Ztschr. klin. Med., 127, 77. Cited by Decherd et al.

Schrumpf, P. (1920). Arch. Mal. Cexur, 13, 168. Cited by Decherd et al.

Tait, J. (1910). Quart. J. exper. Physiol., 3, 185. Cited by Deitz et al.

White, P. D. (1951). Heart Disease. 4th ed. p. 931. Macmillan Co., New York. 